\title{
EFFECT OF SODIUM ALGINATE ON PREVENTION OF HYPERCHOLESTEROLEMIA AND ATHEROSCLEROSIS IN RATS
}

\author{
YULIS KARTIKA $^{1 *}$, HAKIM BANGUN ${ }^{2}$, ROSIDAH $^{1}$ \\ ${ }^{1}$ Department of Pharmacology, Faculty of Pharmacy, University of Sumatera Utara, Medan, Indonesia. ${ }^{2}$ Department of Pharmaceutical \\ Technology, Faculty of Pharmacy, Nanomedicine Centre, University of Sumatera Utara, Medan, Indonesia. Email: yuliskartika@yahoo.co.id
}

Received: 15 January 2017, Revised and Accepted: 07 March 2018

\section{ABSTRACT}

Objective: The present study is to determine the effect of liquid of sodium alginate and powder on the prevention of raising cholesterol levels and atherosclerosis in rats (preventive effect).

Method: Experimental animals were divided into prevention groups. Preventive groups used were 24 normal rats and then divided into four groups, each group consisted of 6 animals: Group 1 (fed a regular diet), Group 2 (fed high cholesterol diet), Group 3 (fed high cholesterol diet and alginate liquid 2\% diet), and Group 4 (fed high cholesterol and alginate powder). Rats are given with cholesterol food, alginate liquid, alginate powder a dose of $1 \mathrm{ml} / 100 \mathrm{~g}$ body weight once a day. Parameters measured were cholesterol level, low-density lipoprotein (LDL) levels, high-density lipoprotein (HDL) levels, triglyceride (TG) level, body weight every week, and histopathologically of the aorta for foam cells examined at the end of the experiment. Analysis of data was performed using one-way ANOVA.

Results: The lipid profiles in the preventive group showed alginate liquid and powder which have the effect of preventing increase total cholesterol, LDL, TG, number of foam cells, and decrease HDL. Diet using alginate powder better than alginate liquid, but the effect was not different significantly $(\mathrm{p}<0.05)$ so do the regular diet, but higher than given with high cholesterol diet significantly $(\mathrm{p}>0.05)$.

Conclusion: This study showed that the alginate liquid and alginate powder have an anti-hypercholesterolemia property which has been proved by preventing increase LDL, TG, and increased HDL levels.

Keywords: Sodium alginate, Cholesterol levels, High-density lipoprotein, Low-density lipoprotein, Triglyceride, Foam cell.

(C) 2018 The Authors. Published by Innovare Academic Sciences Pvt Ltd. This is an open access article under the CC BY license (http://creativecommons. org/licenses/by/4. 0/) DOI: http://dx.doi.org/10.22159/ajpcr.2018.v11i6.24768

\section{INTRODUCTION}

Coronary artery disease (CAD) is one of the most important causes of death all over the world. Hyperlipidemia is one of the risk factors for CAD. Data show that $25-30 \%$ risk of CAD is reduced by treating hyperlipidemia [1]. The increasing morbidity and mortality from coronary heart disease is the biggest challenge to nutritionists and medical scientists all over the world [2].

Hyperlipidemia, hypertension, obesity, raised coagulation factor, and homocysteine are modified risk factors for atherosclerosis. Dyslipidemia is most common risk factor causing ischemic heart disease (IHD) of the elderly population. The underlying mechanism of IHD involves the deposition of serum lipids in coronary arteries, and it results in decreased blood flow to cardiac muscles [3].

Atherosclerosis - cardiovascular disorder which involves progressive narrowing and degeneration of arteries. The oxidative modification of low-density lipoproteins (LDL) in the arterial wall by reactive oxygen species and elevated levels of homocysteine in blood plasma are the key risk factors for atherosclerosis. Importantly, several processes are triggered by other risk factors, including the expression of adhesion molecules, the proliferation and migration of smooth muscle cells, the apoptosis of endothelial cells, the oxidation of lipids, the activation of metalloproteinase, and the alteration of vasomotor activity. Eventually, in its natural progression, calcification of the atheromatous plaque occurs. Depending on the affected artery in the body, the related disorders include coronary heart disease, carotid artery disease, peripheral arterial disease, and chronic kidney disease [4].

Dietary fiber is a collective term for a variety of plant substances that are resistant to digestion by human gastrointestinal enzymes. Dietary fibers classified into two major groups depending on their solubility in water, soluble, and insoluble fibers. Studies have focused on soluble fibers such as oats, psyllium, pectin, and guar gum, and qualitative reviews suggested that these fibers lower total and LDL cholesterol. Water-insoluble wheat fiber and cellulose have no effect unless they displace foods supplying saturated fats and cholesterol [5]. It is thought that soluble fiber lowers blood cholesterol by binding bile acids, which are made from cholesterol to digest dietary fats, and then excreting them [6].

Alginate fiber is a possible source of viscous dietary fiber as a fiber isolate or in algae containing foods. The main constituents of agents are uronic acids (1,4- $\beta$-monophonic and 1,4- $\alpha$-guluronic acids [7] which give the alginate characteristics similar to pectin (galacturonic acid). Fiber from algae is commonly used as a texture modifier in the food industry. However, little is known about its physiologic effects in humans. Sodium alginate (SA) is readily water-soluble and produces a highly viscous gel in a solution containing partially ionized carboxyl groups. Agents have the potential for use as a "functional food" since the production of b-elimination products by bacterial alginate-degrading enzymes may increase the growth of beneficial Bacteroides species of bacteria in the gut [8].

SA is a natural polymer, which is biocompatible and biodegradable. Bangun has reported that ointment with alginate base is highly hydrophilic. It has pseudoplastic rheology and non-irritating properties. In previous Studies, Alginate can be used for the preparation of periodental drug delivery system and gastroretentive drug delivery system of ranitidine $\mathrm{HCl}$, antacids, and amoxicillin [9-13] .

The result of a study by Mushollaeni has reported that the alginate extracted from brown seaweed Sargassum sp. and Turbinaria sp. 
obtained from the rocky beach area Wonosari Yogyakarta has the ability to decrease blood cholesterol levels in hypercholesterolemic rats. Both types of alginate have demonstrated its ability to lower total blood cholesterol levels of rats up to $53 \%$. The cholesterol-lowering effect is caused by the fibers contained in the alginate [14].

The purpose of this research was to test the effect of SA to preventing the increase of rats cholesterol levels, LDL, high-density lipoprotein (HDL), weight, and formation of foam cells and then to compare between liquid and powder most effective in preventing the increase of rats cholesterol levels, LDL, HDL, weight, and formation of foam cells.

\section{MATERIALS AND METHODS}

\section{Materials}

The materials used are SA 500-600 cps (Wako Pure Chemical Industries, Ltd., Japan),distilled water, sugar, nipagin (Merck), ethanol, liquid paraffin (Merck), xylol (Merck), xylene (Merck), hematosilin solution $0.2 \%$ (Merck), a solution of $1 \%$ eosin (Merck), cholesterol reagents (Glory Diagnostic), HDL reagents (Glory Diagnostics), triglyceride (TG) reagents (Glory Diagnostics), goat fat and quail egg yolk obtained from kampong lalang market, cooking oil, normal rat feed (pellets 794P), and high-cholesterol feed (pellets CP511).

Animals used are healthy white male rats weighing 150-200 g were maintained in standard animal house, given standard pellet diets and tap water adlibitum. The rats were fasted for all medications at least 2 weeks before the treatment was given. All the rats were adhered to the standard operation procedures and approved by the Animal Research Ethics Committee of FMIPA University of Sumatera Utara. Experimental animals were divided into four groups in preventive groups.

\section{Method}

\section{Preventive group}

Used 24 were normal rats and then divided into four groups, each group consisting of six rats.

Group I (normal control): Received distilled water and regular diet (pellets 794p).

Group II (negative control): Received 1\% of cholesterol in the high cholesterol feed (goat fat, quail egg yolk, and cooking oil) and pellets CP511 once a day.

Group III (test group): Received 1\% of cholesterol in the high cholesterol feed (goat fat, quail egg yolk, and cooking oil) and alginate liquid $2 \%$ once a day.

Group IV (test group): Received 1\% of cholesterol in the high cholesterol feed (goat fat, quail egg yolk, and cooking oil) and alginate powder $(0.02 \mathrm{mg} / \mathrm{kg}$ p.o) once a day.

High cholesterol food administered to raise blood cholesterol levels of rats was a high-fat suspension preparation prepared by mixing, cooking oil (50\%), goat fat (30\%), and quail yolk (20\%).

This experiment was conducted for 12 weeks. Cholesterol, LDL, HDL, TG and weight were measured once a week. At the end of the experiment, the rats were killed by decapitation, and then, aorta was taken and examined histopathologically.

\section{Determination of cholesterol levels}

This method for the measurement of total cholesterol in serum involves the use of three enzymes: Cholesterol esterase, cholesterol oxidase, and peroxidase. In the presence of the former, the mixture of phenol and 4-aminoantipyrine is condensed by hydrogen peroxide to quinoneimine dye proportional to the concentration of cholesterol in the sample.

Blood Sample was taken every week. Blood taken $0.5 \mathrm{ml}$ was collected using a microcentrifuge tube, and it was centrifuged at $5000 \mathrm{rpm}$ for $20 \mathrm{~min}$, then separated, and taken the serum. Measure $1 \mathrm{ml}$ reagent microcentrifuge cholesterol into the tube, then add $10 \mu \mathrm{L}$ of serum, mixed and incubated for $20 \mathrm{~min}$ at a temperature of $20-25 \mathrm{C}$ or for $10 \mathrm{~min}$ at a temperature of $37^{\circ} \mathrm{C}$. Pour into culvert, then read the absorbance values using a spectrophotometer, at a wavelength of $500 \mathrm{~nm}$.

\section{Determination of HDL levels}

This technique uses a separation method based on the selective precipitation of apolipoprotein $\beta$ - containing lipoproteins (very LDL, LDL, and $\alpha$ by phosphotungstic acid/ $\mathrm{MgCl}_{2}$ ). Sedimentation of the precipitant by centrifugation and subsequent enzymatic analysis of HDL as residual cholesterol is remaining in the clear supernatant.

First, it must be HDL precipitant. Blood was taken $0.5 \mathrm{ml}$ into a microcentrifuge tube, and then blood was centrifuged at $5000 \mathrm{rpm}$ for $20 \mathrm{~min}$, then separated and taken the serum. Then take $0.2 \mathrm{ml}$ of serum sample, add $0.4 \mathrm{ml}$ of precipitant HDL reagent, mix and let stand for $10 \mathrm{~min}$ at room temperature, then centrifuge at $4000 \mathrm{rpm}$ for $10 \mathrm{~min}$, then separate and take the supernatant, and leave for $2 \mathrm{~h}$. Measure $1 \mathrm{ml}$ reagent microcentrifuge cholesterol into the tube, then add $50 \mathrm{~mL}$ of serum, mixed and incubated for $10 \mathrm{~min}$ at a temperature of $20-25^{\circ} \mathrm{C}$ or for $5 \mathrm{~min}$ at a temperature of $37^{\circ} \mathrm{C}$. Pour into culvert, then read the absorbance values using a spectrophotometer, at a wavelength of $500 \mathrm{~nm}$.

\section{Determination of TG levels}

The method is based on the enzymatic hydrolysis of serum or plasma TG to glycerol and free fatty acids by lipoprotein lipase. The glycerol is phosphorylated by adenosine triphosphate in the presence of glycerol kinase to form glycerol-3-phosphate and adenosine diphosphate. Glycerol-3-phosphate is oxidized by glycerophosphate oxidase to form dihydroxyacetone phosphate and hydrogen peroxide. A red chromogen is produced by the peroxidase-catalyzed coupling of 4-aminoantipyrine and phenol with hydrogen peroxide proportional to the concentration of TG in the sample.

Blood was taken $0.5 \mathrm{ml}$ and collected using a microcentrifuge tube, then blood was centrifuged at $5000 \mathrm{rpm}$ for $20 \mathrm{~min}$, then separate and take the serum. Measure $1 \mathrm{ml}$ reagent microcentrifugecholesterol into the tube, then add $10 \mathrm{ml}$ of serum, mixed and incubated for $20 \mathrm{~min}$ at a temperature of $20-25^{\circ} \mathrm{C}$ or for $10 \mathrm{~min}$ at a temperature of $37^{\circ} \mathrm{C}$ Pour into culvert, then read the absorbance values using a spectrophotometer, at a wavelength of $500 \mathrm{~nm}$.

The total cholesterol, HDL, and TG levels were measured using the following formula:

$\mathrm{C}_{\mathrm{LX}}=\mathrm{C}_{\text {Sample }}=\frac{\text { Abs.SamplexConc.Standard }}{\text { Abs.standard }}$

The LDL levels were measured using the following formula:

LDL=Total cholestherol $-\frac{\text { Triglyceridelevels }}{5}-$ HDL levels

\section{Histopathology}

After the tissue was preserved, by immersion in a preservative solution (usually 10\% formalin solution is used), the tissue must be processed into a sliced form. To analyze the structure of the sliced tissue, the preparations already made must be colored. In this research, the staining used is HE staining. The function of haematoxylin in this coloration was to color the nucleus, while the function of eosin was to color the cytoplasm. Foam cells formed in the aortic intima layer, with HE staining, will show large cells with a blue core. Since fat cells will dissolve during the staining process, it will show an empty space between the nucleus and the cell membrane. Foam cells were calculated on 10 field of view, then taken the average value. Determine the aorta on the preparation with 10 times magnification, then enlarge with $\times 400$ enlargement, measure foam cells in the field of view, then the preparations are shifted to the left or right count of visible foam cells, and so on up to ten field of view, the location of observation should not be repeated [15]. 
Statistical analysis

The data were analyzed statistically with pair to t-test using the Statistical Product and Service Solution with a 95\% confidence level 17 version.

\section{RESULTS AND DISCUSSION}

\section{Cholesterol levels}

After induction with high cholesterol feed for 11 weeks, then SA in the form of liquid or in the form of powder was able to prevent raising cholesterol levels in male Wistar rats. There was no statistically significant difference between liquid $(431.5 \pm 29.03)$ and powder (402.42 \pm 18.9$)$. Negative control $(819.33 \pm 22.48)$ is significantly different compared to normal (409 \pm 24.94$)$, alginate liquid, and alginate powder. This can happen because at normal is not given any treatment except regular feeding and drinking ad libitum. Fig. 1 shows group that given with high cholesterol for 11 weeks increasing cholesterol levels, but group that given with regular diet not increasing cholesterol level, so cholesterol levels in this group increased, according to that the liver and intestines donate $10 \%$ of cholesterol levels of the total synthetic total in the body. The results of cholesterol levels in rats fed liquid and powder alginate together with high cholesterol diet as shown in Fig. 1.

\section{LDL levels}

SA in both liquid and powder form was able to prevent the increase in LDL levels in male Wistar rats. There was no statistically significant difference between alginate syrup $(283.97 \pm 29.52)$ and alginate powder (270.12 \pm 37.87$)$. Fiber in food can lower blood cholesterol levels. The mechanism is related to the ability of dietary fiber to form a gel in the stomach and increase the excretion of feces [16-18]. Dietary fiber in the intestine can reduce the absorption of cholesterol in the hepatic circulation and immediately removing it through the feces [19]. Decreasing the amount of cholesterol that is absorbed is also caused by increased fat excretion and bile acids. Bile acids are the end products of metabolism of cholesterol. Bile acids formed from cholesterol in the liver. Dietary fiber can bind to bile acids, and then, the results will be excreted through feces. The high excretion of bile acids indicates the higher the amount of cholesterol that has been converted into bile acids to emulsify fat. The result of this mechanism is lower levels of total cholesterol and LDL [20]. The results of LDL levels in rats fed liquid and powder alginate together with high cholesterol diet as shown in Fig. 2.

\section{HDL levels}

SA in the form of syrup or in the form of powder was able to prevent the decrease in HDL levels in male Wistar rats. There was no statistically significant difference between the syrup $(624.25 \pm 78.87)$ and powder (603.17 \pm 43.21 ). Increasing concentrations of HDL particles are strongly associated with decreasing accumulation of atherosclerosis within the walls of arteries. This is important because atherosclerosis eventually results in sudden plaque ruptures, cardiovascular disease, stroke, and other vascular diseases. HDL particle is sometimes referred to as "good cholesterol" because they can transport fat molecules out of artery walls, reduce macrophage accumulation, and thus help prevent or even regress atherosclerosis. However, studies have shown that HDL lacking mice still have the ability to transport cholesterol to bile, suggesting that there is an alternative mechanism for cholesterol removal [21]. The results of HDL levels in rats fed liquid and powder alginate together with high cholesterol diet as shown in Fig. 3.

\section{TG levels}

SA in the form of syrup and in the form of powder was able to prevent the increase of TG levels in male Wistar rats. There was no statistically significant difference between the syrup (1062.25 \pm 78.97$)$ and powder $(1063.75 \pm 67.74)$. Alginate contains fiber that can bind cholesterol, so it does not spread in the blood so that cholesterol decreases. Cholesterol decreases, TG levels in the blood also decreased. However, the relative negative impact of rising levels of

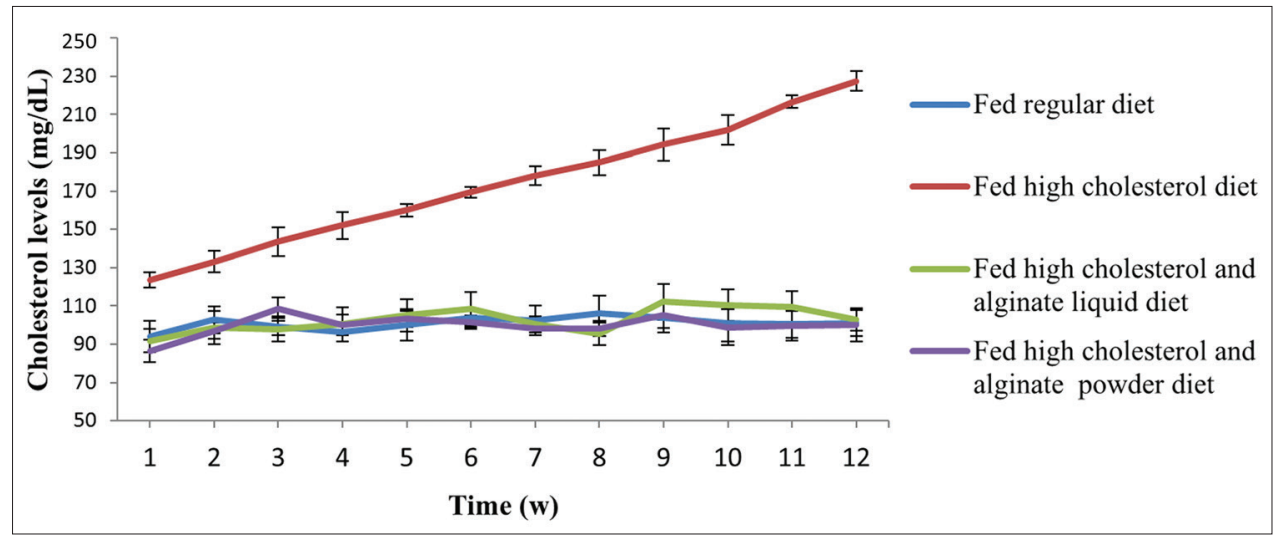

Fig.1: Effect of alginate liquid and powder on the inhibition of rats cholesterol increase after being fed a high fat meal to the measurement time

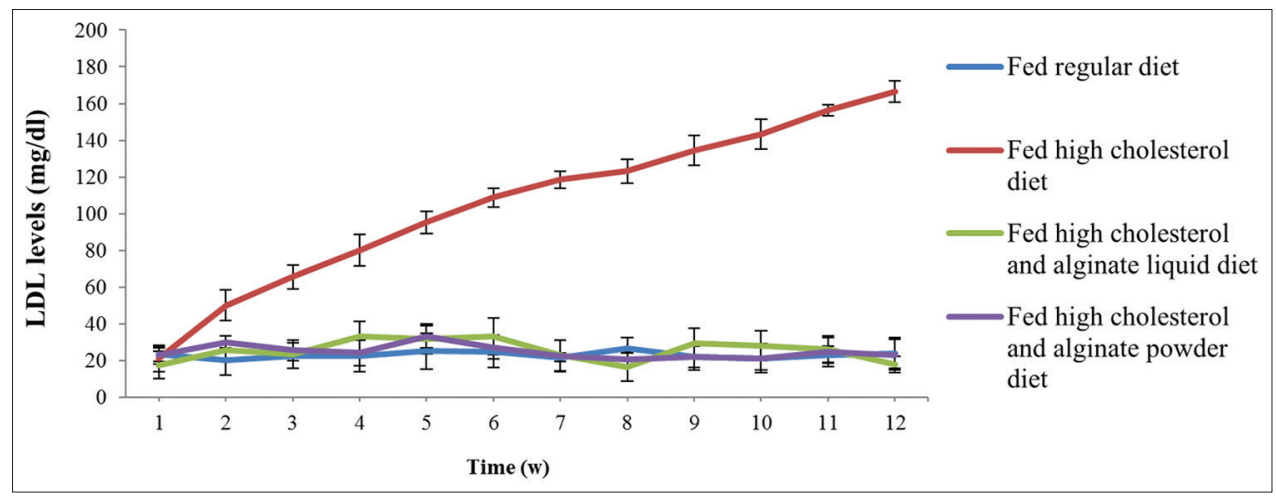

Fig. 2: Effect of alginate liquid and powder on the inhibition of the rats LDL increase after being fed a high fat meal to the measurement time 
TGs compared to that of LDL:HDL ratios is as yet unknown. The risk can be partly accounted for by a strong inverse relationship between TG level and HDL cholesterol levels. TG levels are also reduced by moderate exercise and by consuming omega 3 fatty acids from algae, fish, flaxseed oil, fiber, and other sources [22]. The results of HDL levels in rats fed liquid and powder alginate together with high cholesterol diet as shown in Fig. 4.

After being fed a high-fat meal to the measurement time.

\section{Weight loss}

SA in the form of liquid or in the form of powder was able to prevent weight gain in male Wistar rats. There was no statistically significant difference between liquid $(936.11 \pm 103.63)$ and powder (969.25 \pm 19.13$)$. An additional benefit of alginate is that it is able to form both ionic and acidic gels. This may be possible mechanism for a reduction in the digestibility of macronutrients and reduction in hunger seen after consumption of alginates in mixed diets partially because of the viscosity increase caused by gel formation in the stomach at low $\mathrm{pH}$ [23-25]. The results of weight in rats fed liquid and powder alginate together with high cholesterol diet as shown in Fig. 5.

\section{The formation of foam cells}

$\mathrm{SA}$ in both liquid and powder form can inhibit the formation of foam cells. There was no statistically significant difference between liquid $(3.83 \pm 1.30)$ and powder $(2.33 \pm 1.22)$ in inhibiting the formation of foam cells.

In chronic hyperlipidemia, lipoproteins aggregate within the intima of blood vessels and become oxidized by the action of oxygen free radicals generated either by macrophages or endothelial cells. The macrophages engulf oxidized LDLs by endocytosis through scavenger receptors, which are distinct from LDL receptors. The oxidized LDL accumulates in the macrophages and other phagocytes, which are then known as foam cells [26]. Foam cells form the fatty streaks of the plaques of atheroma in the tunica intima of arteries. LDL cholesterol is contained in a foam cell. LDL is also known as "bad" cholesterol. It becomes a marker for atherosclerosis. Foam cells are the body's way of trying to get rid of bad cholesterol from the blood vessels. Foam cells do not give off any explicit signs or symptoms, but they are part of the origin of atherosclerosis. Foam cells are very small in size and can only be truly detected by examining a fatty plaque under a microscope after it is removed from the body. HDL cholesterol is good cholesterol, and it removes harmful bad cholesterol from where it does not belong (Table 1). The histopatology of aorta rats can be shown in (Fig. 6-9)

\section{CONCLUSION}

- The results indicate that alginate liquid and alginate powder are useful to prevent atherosclerosis, the blood cholesterol, LDL, HDL, and TG levels.

- Liquid and alginate powder have the same effect in preventing elevated cholesterol, LDL, HDL, TG, and weight levels and preventing the formation of foam cells.

\section{AUTHOR'S CONTRIBUTIONS}

Yulis Kartika conducted this study. Hakim Bangun planted and designed this study, and Rosidah supported the conduction of the study.

CONFLICT OF INTEREST

The authors declare that they have no conflict of interest.

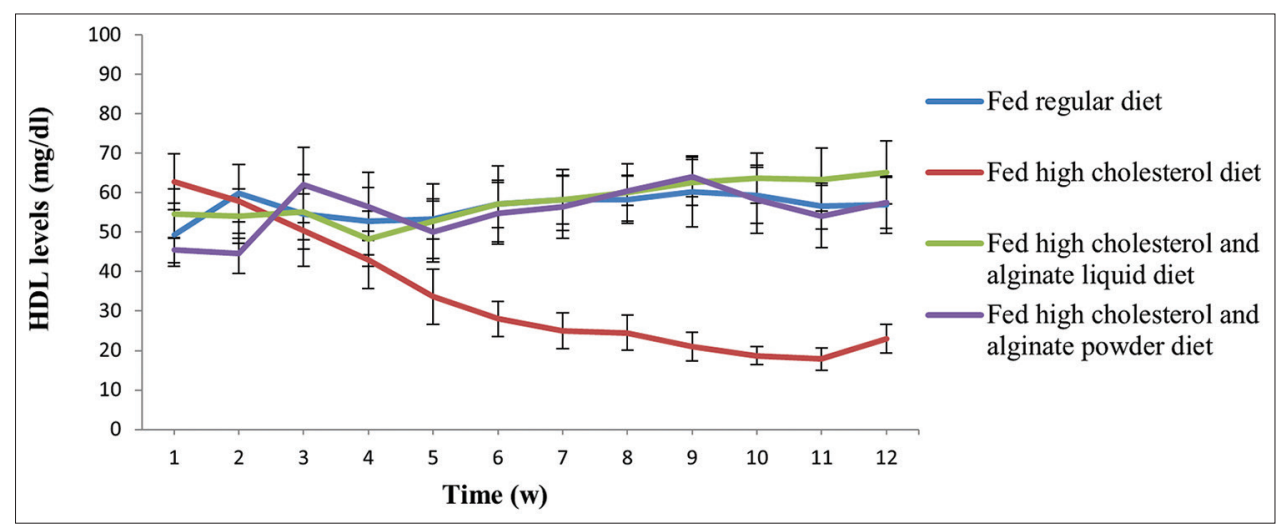

Fig. 3: Effect of alginate liquid and powder on the inhibition of rats HDL decrease after being fed a high fat meal to the measurement time

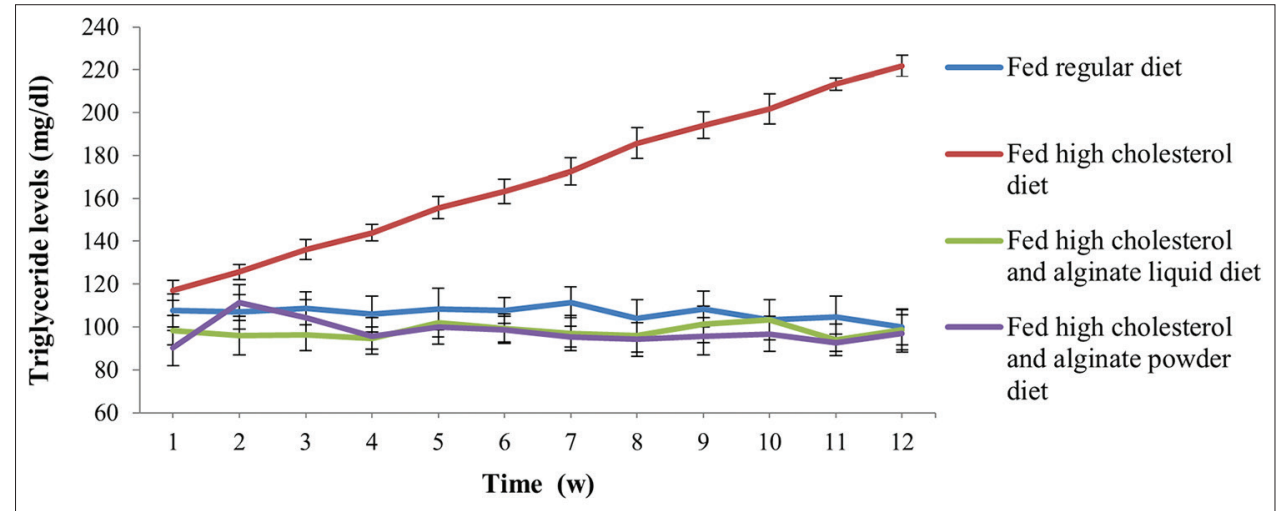

Fig. 4: Effect of alginate liquid and powder on the inhibition of rats triglyceride increase After being fed a high fat meal to the measurement time 


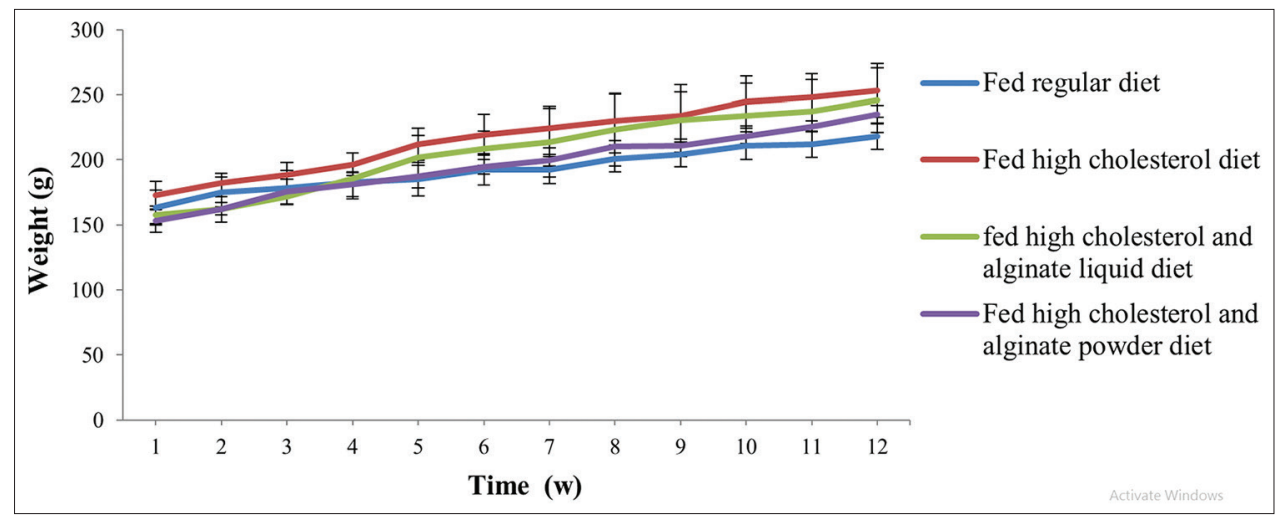

Fig. 5: Effect of alginate liquid and powder on body weight of rats after feeding a high cholesterol diet on the measurement time

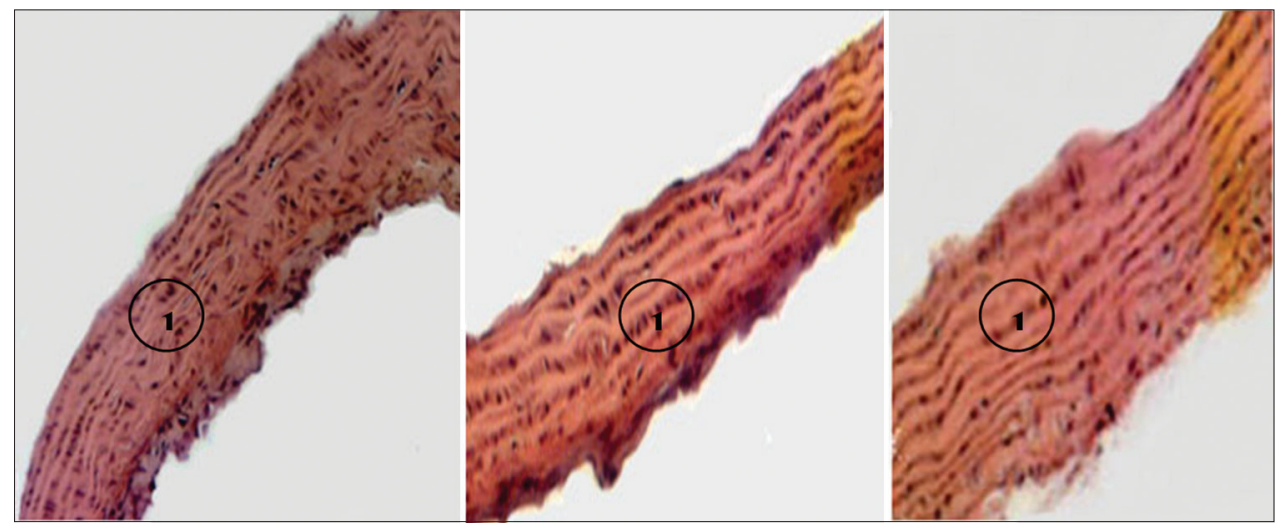

Fig. 6: The histopathological aorta of rats after 11 weeks for feeding regular diet 1. Intima layers. 2. Foam cells

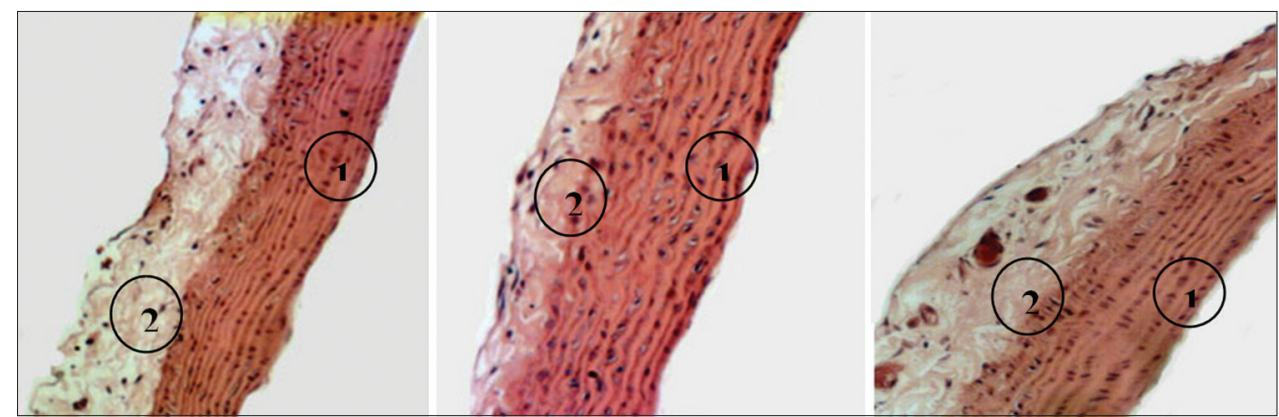

Fig. 7: The histopathological aorta of rats after 11 weeks for feeding high cholesterol diet. Aorta showing multiple foam cells 1. Intima layers. 2. Foam cells

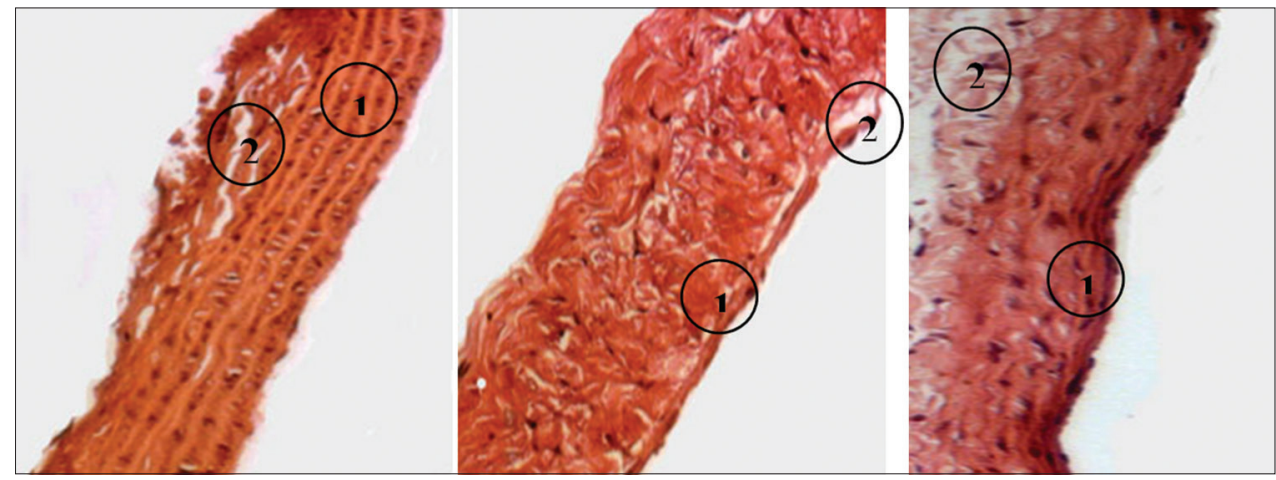

Fig. 8: The histopathological aorta of rats after 11 weeks for feeding high cholesterol and alginateliquid diet. Aorta showing few foam cells 1. Intima layers. 2. Foam cells 


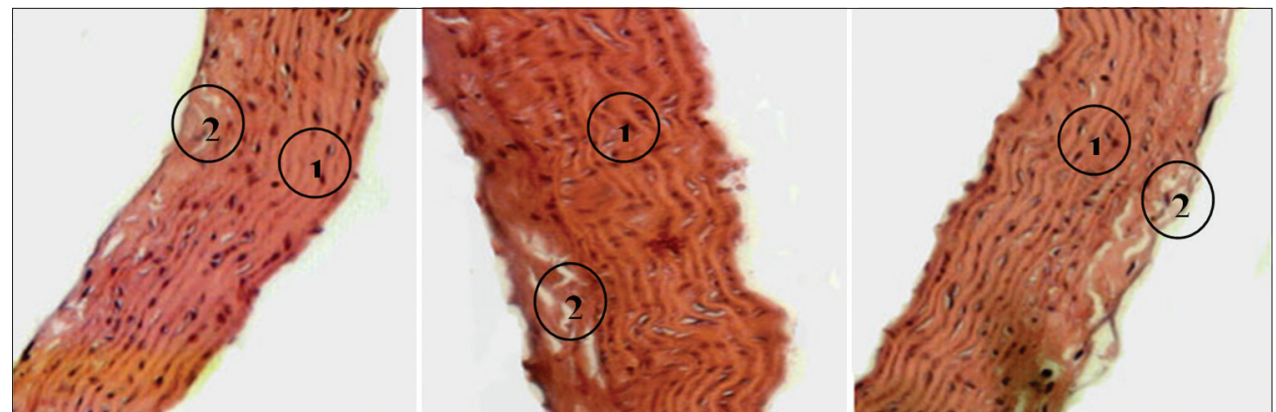

Fig. 9: The histopathological aorta of rats after 11 weeks for feeding high cholesterol and alginate powder diet. Aorta showing few foam cells 1. Intima layers. 2. Foam cells

Table 1: Foam cells of preventive groups $(\mathrm{mg} / \mathrm{dL}$ weeks) $\mathrm{n}=6$

\begin{tabular}{llll}
\hline Normal & $\begin{array}{l}\text { Positive if } \\
\text { control }\end{array}$ & Alginate liquid & Alginate powder \\
\hline $1.00 \pm 1.26$ & $10.5 \pm 2.49$ & $3.83 \pm 1.30$ & $2.33 \pm 1.22$ \\
\hline
\end{tabular}

\section{REFERENCES}

1. Tajuddin M, Ahmad NN. Effect of an Unani formulation on lipid profile in rat. Indian J Pharmacol 2006;38:56-7.

2. Pamidiboina V, Razdan R, Hariprasad MG. Evaluation of the antihyperlipidemic, cardioprotective activity of a polyherbal formulation. Int J Pharm Pharm Sci 2010;2:86-7.

3. Parasuraman S, Kumar EP, Kumar A, Emerson SF. Antihyperlipidemic effect of triglize, a polyherbal formulation. Int J Pharm Pharm Sci 2010;2:118-9.

4. Subhapriya S, Tomi L, Padmanaban VC. Atherosclerosis: Critical role of oxidation and inflammation. Int J Pharm Pharm Sci 2013;5:6-8.

5. Brown L, Rosner B, Willett WW, Sacks FM. Cholesterol-lowering effects of dietary fiber: A meta-analysis. Am J Clin Nutr 1999;69:30-42.

6. Glore SR, Van TD, Knehans AW, Guild M. Soluble fiber and serum lipids: A literature review. J Am Dietetic Assoc 1994;94:425-36.

7. Martin G. Evaluation toxilogiqueet nutritionelle des alginates. The afinition, structure, fabrication propieate as et applications (Toxicological and nutritional evaluation of alginates, Definition, structure, manufacturing properties and applications). Sci Aliments 1986;6:473-86.

8. Michel C, Macfarlane GT. Digestive fates of soluble polysaccharides from marine macroalgae: Involvement of the colonic microflora and physiological consequences for the host. J Appl Bacteriol 1996;80:349-69.

9. Ariyana A, Sinurat D, Ervina D, Bangun H. Formulation and in vitro evaluation of alginate based metronidazole periodontal gel. Asian J Pharm Clin Res 2014;7:223-7.

10. Mariadi, Bangun H, Karsono. Formulation and in vitro evaluation of gastroretentive drug delivery system of antacids using alginate-chitosan film. Int J Pharm Tech Res 2015;8:1, 2.

11. Adliani N, Bangun H, Karsono. Preparation and evaluation of floating- mucoadhesive alginate beads as gastroretentive drug delivery system of antacids. Int J Pharm Tech Res 2016;9:212-22.
12. Arianto A. Antiulcer effect of gastroretentive spherical matrices of alginate- chitosan containing ranitidine $\mathrm{HCl}$. Int $\mathrm{J}$ Pharm Tech Res 2016;9:342-52.

13. Arianto A, Bangun H, Yohana A, Silalahi J. Floating gastroretentive of amoxicillin using hard alginate capsules and its anti bacterialactivites. Int J Pharm Tech Res 2017;10:413-9.

14. Mushollaeni W. Decreasing blood cholesterol levels in rats induced by alginate of Sargassum duplicatum and Turbinaria sp. Derived from Yogyakarta. Asian J Agric Food Sci 2011;3:148-55.

15. Hadjipour N. Histopathological comparison of gentamycin and amikacin nephrotoxicity in rabbits. J Anim Vet Adv 2011;10:1003-6.

16. Behall KM. Dietary fiber: Nutritional lessons for macronutrient substitutes. Ann N Y Acad Sci 1997;819:142-54.

17. Choudhary MI, Naheed S, Jalil S, Alam JM, Atta-ur-Rahman. Effects of ethanolic extract of iris germanica on lipid profile of rats fed on a high-fat diet. J Ethnopharmacol 2005;98:217-20.

18. Moriceau S, Besson C, Levrat MA, Moundras C, Rémésy C, Morand C, et al. Cholesterol-lowering effects of guar gum: Changes in bile acid pools and intestinal reabsorption. Lipids 2000;35:437-44.

19. Samarghandian S, Hadjzadeh MA, Davari AS, Abachi M. Reduction of serum cholesterol in hypercholesterolemic rats by Guar gum. Avicenna J Phytomed 2011;1:36-42.

20. Anderson $\mathrm{H}$. Effects of carbohydrates on the axcretion of bile acids, cholesterols, and fat from the small bowell. Am J Clin Nutr 1994;59:785.

21. Zhang DW, Garuti R, Tang WJ, Cohen JC, Hobbs HH. Structural requirements for PCSK9-mediated degradation of the low-density lipoprotein receptor. Proc Natl Acad Sci U S A 2008; 105:13045-50.

22. Davidson $\mathrm{MH}$. Pharmacological therapy for cardiovascular disease. Pharmacol Ther Cardiovasc Dis 2008;141-42.

23. Draget KI, Stokke RT, Yuguchi Y, Urakawa H, Kajiwara K. Small angle $\mathrm{X}$-ray scattering and reological characterization of alginate gels. 3. Alginic acid gels. Research support, non Us. Biomacromolecules 2003;4:1661-8.

24. Seal CJ, MathersJC.Comparative gastrointestinal and plasma cholesterol responses of rats fed on cholesterol-free diets supplemented with guar gum and sodium alginate. Br J Nutr 2011;5:317-24.

25. Wolf BW, Lai CS, Kipnes MS, Ataya DG, Wheeler KB, Zinker BA, et al. Glycemic and insulinemic responses of nondiabetic healthy adult subjects to an experimental acid-induced viscosity complex incorporated into a glucose beverage. Nutrition 2002;18:621.

26. Kumar A, Fausto A. Robbins and Cotran: Pathologic Basis of Disease. $8^{\text {th }}$ ed., International ed. Philadelphia: Saunders Elsevier; 2010. p. 500-1. 